\title{
Influence of insoluble aerosols on the heat- exchanging characteristics of the SPHR CV in the case of severe accidents
}

\author{
Aleksandr Nigay $^{1, *}$, and Natalya Ivanova ${ }^{1}$ \\ ${ }^{1}$ National Research Tomsk Polytechnic University, 634050 Tomsk, Russia
}

\begin{abstract}
Analysis of the processes in severe accidents at nuclear power plants has allowed distinguishing four characteristic stages of the accident, which differ in condensation rates, concentration and composition of aerosols (table 1) [1]. The released aerosol may condense on the heat transfer surfaces and reduce the effectiveness of the work of PCHRS under severe accident conditions at the deposition of insoluble aerosols on its heat transfer surfaces.
\end{abstract}

\section{Introduction}

Analyzing the consequences of the accident at Fukushima-1 occurred on 11 March 2011 in Japan, in [2] assess the environmental, social and economic damage to the population and the state. Received IPSDAE of RAS result of processing of the accumulated by the middle of 2012 information helped to identify the main causes of the accident: deprecated NPP project, the lack of passive safety systems [2].

Table 1. Stages of the accident at the NPP.

\begin{tabular}{|c|c|c|c|c|}
\hline \multirow{2}{*}{ Mode } & \multicolumn{4}{|c|}{ Stages of the accident } \\
\hline & I & II & III & IV \\
\hline Explanation & $\begin{array}{c}\text { Main output } \\
\text { of aerosol } \\
\text { fission } \\
\text { products }\end{array}$ & $\begin{array}{l}\text { Output of aerosols } \\
\text { from melt at bottom } \\
\text { of reactor vessel }\end{array}$ & $\begin{array}{l}\text { Output of aerosols } \\
\text { from melt to site of } \\
\text { localization of melt }\end{array}$ & $\begin{array}{l}\text { Deposition of } \\
\text { aerosols after their } \\
\text { release in } \\
\text { containment }\end{array}$ \\
\hline $\begin{array}{l}\text { The duration of } \\
\text { deposition of } \\
\text { aerosols, sec }\end{array}$ & 2000 & 6000 & 7000 & 35000 \\
\hline Fission products & $\begin{array}{c}\mathrm{Cs}_{2} \mathrm{MoO}_{4} \\
(100 \%)\end{array}$ & $\begin{array}{c}\mathrm{Fe}(20.58 \%) ; \\
\mathrm{Cr}(15.81 \%) ; \\
\mathrm{Ni}(2.21 \%) ; \\
\mathrm{Nd}_{2} \mathrm{O}_{3}(1.23 \%) ; \\
\mathrm{Zr}(0.19 \%) ; \\
\mathrm{Mn}(59.98 \%)\end{array}$ & $\begin{array}{c}\mathrm{Fe}(17.7 \%) \\
\mathrm{ZrO}_{2}(8.5 \%) \\
\mathrm{MnO}(51.2 \%)\end{array}$ & - \\
\hline
\end{tabular}

${ }^{*}$ Corresponding author: nigayalexandr@mail.ru 
The aim of the present work is to prove efficiency of PCHRS under severe accident conditions at the deposition of insoluble aerosols in the heat exchanging structures.

\section{The methodology of experiment}

For the research made experimental unit, shown in a simplified technological scheme (figure 1).

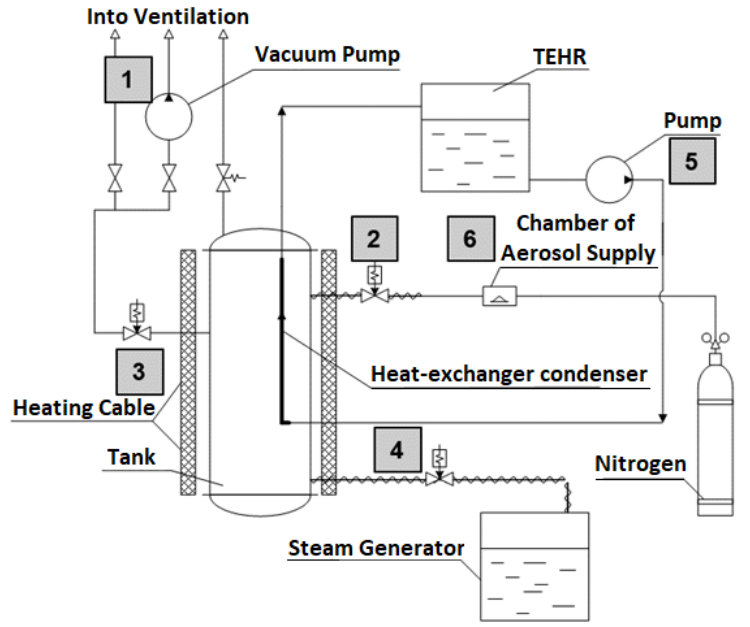

Fig. 1. Simplified technological scheme of experimental unit for research.

The methodology of the experiment:

Heat-exchanger condenser is installed into the tank.

1) Firstly, air is evacuated from the tank;

2) Then nitrogen is supplied;

3) Then tank heats to a predetermined temperature;

4) Next, in the heated tank supply steam. When temperature and pressure reached the predetermined value, the tank of aged 10-20 minutes for stabilize all parameters.

5) Further to the heat-exchanger condenser water is supplied.

6) Upon reaching stationary conditions (water temperature, temperature and pressure of the vapor environment) in the tank is start model of mixture of powders in the carrier gas is nitrogen. Turn on the countdown.

Simulators of fission products for the produce of aerosol take from industrial micron and nanosized powders. In the tank under the pressure of gas-vapor mixture on the heatexchanger condenser of the condensation of vapor and aerosol. In the transition between stages, the temperature inside the tank is reduced by reducing the temperature of the container wall operated from a PC. Release of excessive pressure from the tank is carried on in the ventilation system through vent line. All operation in automatic mode [3-4].

\section{The results of the research}

Analysis of aerosols deposited on the heat exchange surface.

Heat exchanger is made of stainless steel $08 \mathrm{X} 18 \mathrm{H} 10 \mathrm{~T}$, its chemical composition is shown in Table 2 in mass \%.

Table 2. Chemical composition of the steel $08 \mathrm{X} 18 \mathrm{H} 10 \mathrm{~T}$ as per GOST Standard $5632-72$. 


\begin{tabular}{|c|c|c|c|c|c|c|c|c|c|c|c|}
\hline $\begin{array}{c}\text { Chemical } \\
\text { element }\end{array}$ & C & $\mathrm{Si}$ & $\mathrm{Mn}^{*}$ & $\mathrm{Ni}^{*}$ & $\mathrm{~S}$ & $P$ & $\mathrm{Cr}^{*}$ & $\mathrm{Cu}$ & C & $\mathrm{Ti}$ & $\mathrm{Fe}^{*}$ \\
\hline $\begin{array}{l}\text { Element } \\
\text { ratio }\end{array}$ & $\begin{array}{l}\infty \\
0 \\
0 \\
0 \\
0 \\
0 \\
0\end{array}$ & $\begin{array}{l}\infty \\
\dot{0} \\
\stackrel{0}{0} \\
\stackrel{0}{\rho}\end{array}$ & $\begin{array}{l}\sim \\
\stackrel{1}{\rho} \\
\stackrel{\rho}{\rho}\end{array}$ & $\bar{z}$ & $\begin{array}{l}\tilde{o} \\
\dot{0} \\
0 \\
0 \\
0 \\
0\end{array}$ & $\begin{array}{l}\tilde{n} \\
\hat{o} \\
\dot{0} \\
0 \\
\stackrel{0}{\rho}\end{array}$ & $\begin{array}{l}a \\
\stackrel{1}{I}\end{array}$ & $\begin{array}{l}n \\
0 \\
0 \\
0 \\
\rho\end{array}$ & $n$ & $\hat{0}$ & 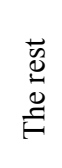 \\
\hline
\end{tabular}

*- matching components included in the composition of steel and aerosol

The steel contains some elements as basis and alloying, which are also included in the aerosol components, and it is not possible to discover their distribution in the aerosol deposited on the heat exchanger surface. In this regard, replicas were prepared from the tube surface on the conductive carbon tape in order to determine the elemental composition of the aerosol deposited on the heat exchanger. Then, the replicas were analyzed on electron microscope JEOL JSM 6000 Neo Scop with the attachment EDS (elemental analysis). The results of the elemental composition and morphology of aerosol deposited on the heat exchanger-condenser are presented in the figures below.

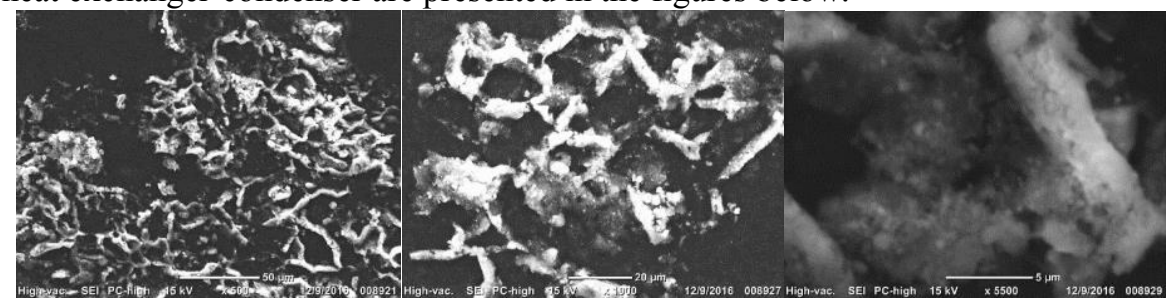

Fig. 2. Micrograph of the aerosols deposited on the heat exchanger-condenser with the low part.

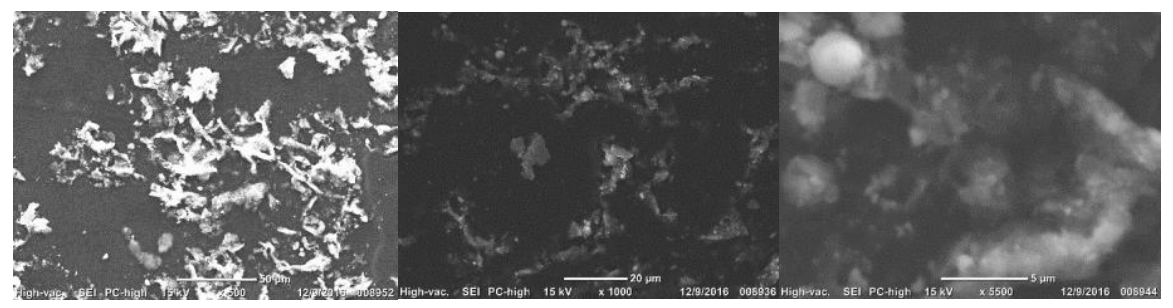

Fig.3. Micrograph of the aerosols deposited on the heat exchanger-condenser with the middle part.

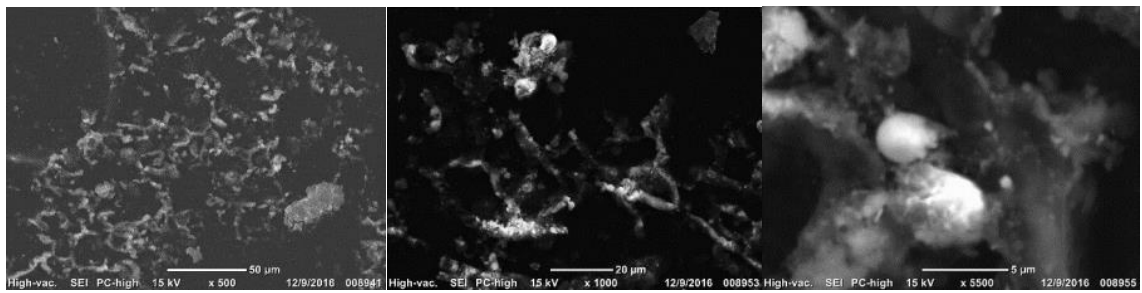

Fig.4. Micrograph of the aerosols deposited on the heat exchanger-condenser with the high part.

Aerosols from the vapor-gas space deposit on the surface of the heat exchangercondenser, the nature of deposition and composition of the deposited aerosols along the length of the heat exchanger depends on the experimental parameters and the location of sampling collection on the heat exchanger.

At the top of the heat exchanger, the aerosol does not create a continuous coating, but precipitates in an isle structure. These isles present elongated formations, with the length (20-30 $\mu \mathrm{m})$ several times greater than the width $(3-5 \mu \mathrm{m})$. These formations have a loose structure, single particles of $0.3-0.7 \mu \mathrm{m}$ and 5-7 $\mu \mathrm{m}$ in size are seen on the surface. 
Elemental composition of the aerosol is represented by $\mathrm{Cs}$ and Mo as basic elements and $\mathrm{Si}$ and $\mathrm{Fe}$ as impurities from the initial powder $\mathrm{Cs} 2 \mathrm{MoO} 4$.

In the middle part of the heat exchanger, the area covered by the aerosol becomes smaller, the length and thickness of the formations decreases. With a larger magnification, a loose surface layer is seen, where individual particles of both micron and nanoscale are distinguishable. Elemental composition of the aerosol is similar to the composition from the top of the heat exchanger, but the intensity of the main elements is lower.

In the lower part of the heat exchanger, the aerosol is deposited by even smaller fragmented "isles". The ratio of length and width $((10-20) \mu \mathrm{m}$ to $(1-3) \mu \mathrm{m})$ of individual elements decreases significantly. Single aerosol particles with sizes ranging from fractions of microns to several microns can also be observed on the surface loose layer. The elemental composition of the aerosol is similar to that of the upper and middle parts of the heat exchanger.

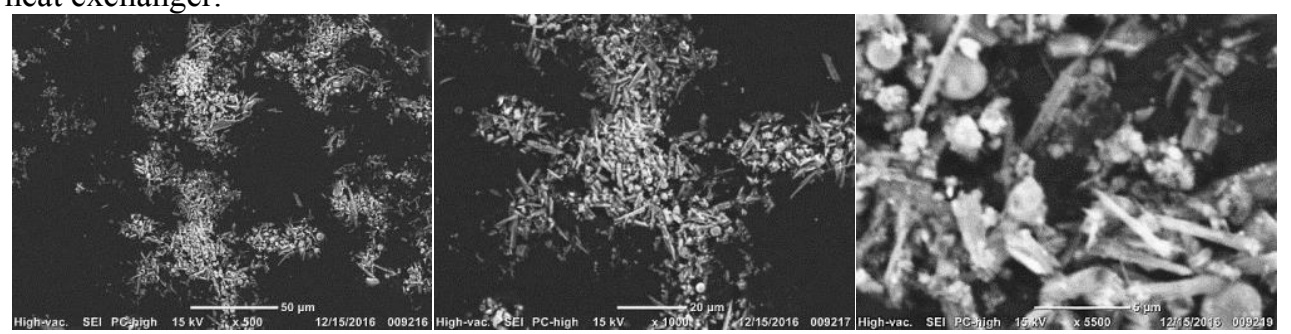

Fig. 5. Micrograph of the aerosols deposited on the heat exchanger-condenser with the low part.

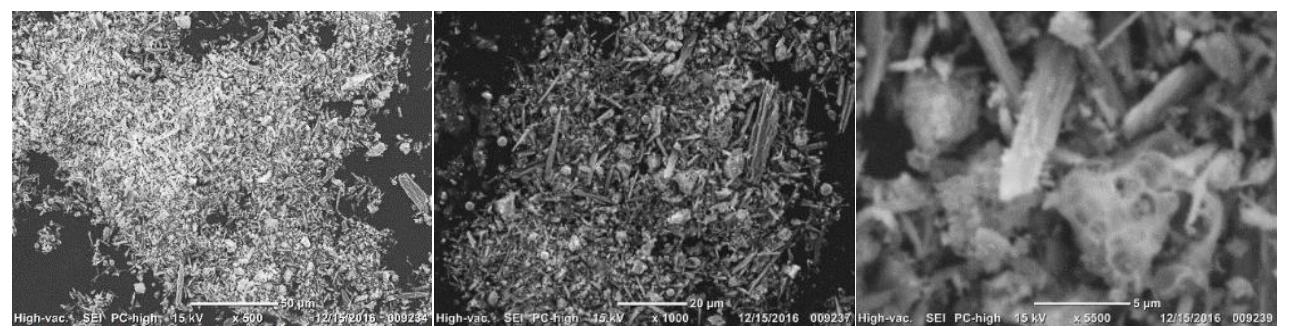

Fig. 6. Micrograph of the aerosols deposited on the heat exchanger-condenser with the middle part.

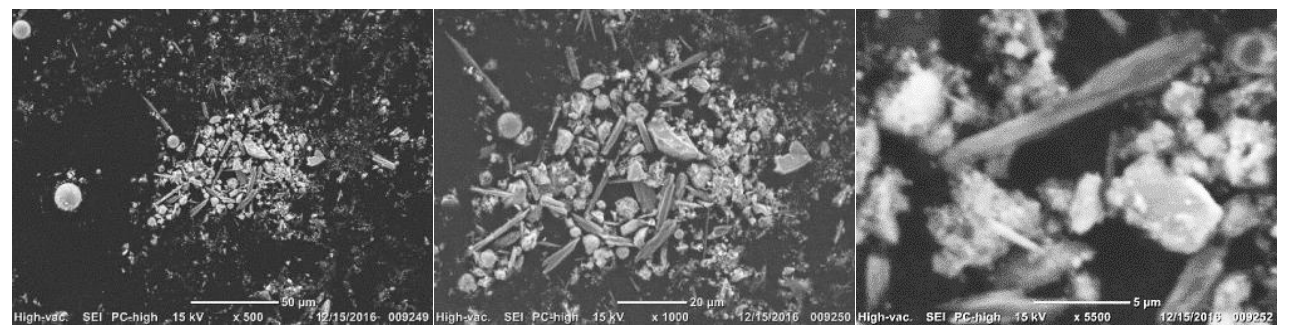

Fig. 7. Micrograph of the aerosols deposited on the heat exchanger-condenser with the high part.

For experiment No. 4, aerosol deposition was carried out in four stages. At the end of the experiment, samples were collected and replicas were prepared.

According to electron microscopy, local deposition of the aerosol with the sizes of up to 40-50 microns occurs in the upper part of the heat exchanger. These structures consist of individual particles of an elongated shape with well-defined boundaries and with different sizes from 5 to $20 \mu \mathrm{m}$. Nano sized particles are located on the surface of elongated particles. Elemental analysis of the aerosol of the heat exchanger deposited on the surface showed the presence of the following elements in the deposited aerosol: $\mathrm{Mn}$ - basic, $\mathrm{Cr}$ basic, $\mathrm{Fe}$ - basic, $\mathrm{Zr}$ - basic. The rest of the aerosol components were not detected. 
In the middle part of the heat exchanger, the deposited aerosol covers a much larger area. The aerosol is disposed on the heat exchanger in the form of elongated irregularly shaped particles, and in the form of initial particles of an irregular detrital form. The elemental composition of the aerosol shows the presence of the following elements introduced during the experiment: $\mathrm{Mn}$ - basic, $\mathrm{Cr}$ - basic, $\mathrm{Fe}$ - basic, $\mathrm{Zr}$ - basic. The rest of the aerosol components were not detected.

In the lower part of the heat exchanger, the aerosol is deposited as a cluster of separate particles and in the form of agglomerates. Elemental composition of the aerosol is similar to the composition of the aerosol from the middle part of the heat exchanger: $\mathrm{Mn}$ - basic, $\mathrm{Cr}$ basic, $\mathrm{Fe}$ - basic, $\mathrm{Zr}$ - basic. The intensity of reflexes is significantly lower than on the middle and upper parts of the heat exchanger.

Compiled tables of thermophysical characteristics [5-6].

\section{Conclusion}

1. The study of the structure of aerosol deposited on the heat exchanger tube at different stages of the heat exchange process simulating the development of severe accidents showed:

a) The maximal deposition of the aerosol is fixed in the middle part of the heat exchanger tube;

b) The deposited aerosol does not form a continuous coating on the heat exchanger tube, the thickness of the local sections of the deposited aerosol is up to $10 \mu \mathrm{m}$;

c) Element analysis of the deposited aerosol showed the presence of all elements introduced in the composition of the FPI.

2. The experimental determination of the coefficient of thermal conductivity of the witness samples, for which the most conservative conditions for aerosol deposition were realized, did not reveal significant changes in the thermal conductivity coefficient.

3. The study of the structure of the aerosol deposited on the tube and the measured coefficients of thermal conductivity of the witness samples with aerosol makes it possible to state that the deposited aerosol does not significantly influence the heat exchange process between the vapor-gas mixture and the water flowing in the heat exchanger.

4. The introduction a boric acid aerosol into the vapor-gas mixture with simultaneous presence of an FPI aerosol slightly increases the heat transfer coefficient from vapor to water.

\section{References}

1. I.L. Kozlov, Works of the Odessa Polytechnic University, 1 (45), 65 (2015)

2. D.V. Aron, M.V. Pavlova, S.V. Panchenko, Bulletin of the Russian Academy of Sciences, Energy, 5, 65 (2013)

3. E.V. Kravchenko, A.G. Nigay, MATEC Web Conf., 37, 01037 (2015), DOI: $10.1051 /$ matecconf $/ 20153701037$

4. A.G. Nigay, J.Z. Vasileva, Smart energy systems: proceedings of the IV International youth forum, 1, 119 (2016)

5. V.V. Medvedev, N. Galchenko, A.G. Nigay, D. Sivkov, MATEC Web Conf., 72, 01032 (2016), DOI: 10.1051/matecconf/20167201032

6. N.A. Ivanova, E.E. Bulba, MATEC Web Conf., 110, 01020 (2017), DOI: 10.1051/matecconf/201711001020 